\title{
LA GEOPOLÍTICA EN SUDAMÉRICA: CONFLICTOS POTENCIALES Y EFECTOS GLOBALES
}

\author{
José Luis Cadena Montenegro \\ Universidad Santo Tomás \\ Bogotá D.C., Colombia
}

\section{RESUMEN}

La importancia geopolítica de Sudamérica frente a los planes de los Estados Unidos, para mantener la hegemonía global, está intrínsecamente vinculada a su dimensión económica y comercial. Recursos estratégicos como el agua y el petróleo escasean a nivel mundial y las principales reservas se ubican en Sudamérica; por esa razón es importante para los Estados Unidos, declarar estos sitios como propiedad de la humanidad, para administrarlos en el futuro con el pretexto de la «destrucción del medio ambiente por parte de sus pobladores». Los problemas que contribuyen a la destrucción del entorno son ante todo, acciones de índole antrópica y cultural, cuyas raíces se encuentran en el orden económico y social que determina las formas de vida de una sociedad estimulando el consumo mediante la aculturación. Paradójicamente, el subcontinente con mayor biodiversidad, afronta problemas de pobreza, hambre y violencia que lo mantienen en el grupo del Tercer Mundo. La dirigencia política sudamericana se ha enfrascado en discusiones ideológicas en desuso, olvidándose del desarrollo humano y condenando a sus países a la condición de proveedores de comoditis. No es descartable que en Sudamérica la guerra intente resolver problemas que la política ha dejado añejar.

Palabras clave: Sudamérica, geopolítica, comoditis, conflictos, geoeconomía, desarrollo humano.

\section{ABSTRACT}

The South American geopolitical importance in the plans of the United States and their idea of keeping the global hegemony is intrinsically related to their economical and commercial issues. There are some strategic resources like water and oil which are in short supply; these can be found in South America. U.S. is interested in declaring these mankind's resources property to be able to manage them in a long term basis by using the excuse of the of the environment destruction by its settlers. The main problems which may cause this destruction are related to cultural and human reasons; all of them have something to do with economical and social matters stating the way of behaving in a society and stimulate consumption through culture. This southern part of the continent 
which has paradoxically the biggest biodiversity is facing hunger and violence problems that make it remain in the group of developing nations or under developed. The leading south American countries are at a standstill, discussing nonsense ideas and forgetting human development, taking their countries to become commodities suppliers. There may be a war in order to solve all the problems that politians have not been able to solve yet.

Key words: South America, Geopolitics, commodities, conflicts, geo-economics, human development.

\section{Introducción}

Los estudios de geopolítica en Latinoamérica y en especial sobre el subcontinente sudamericano, muestran que los Estados Unidos, tradicionalmente han mantenido un liderazgo apoyado en diferentes métodos pero en todas las oportunidades, fundamentado en el interés de practicar la doctrina del destino manifiesto ${ }^{1}$. En el siglo XXI, la primera potencia mundial no renuncia a mantener puntos estratégicos para el dominio económico y militar en todo el continente, pues desde tiempo atrás han manifestado que «el nuestro es un derecho amparado en el destino manifiesto a extendernos sobre el continente entero. Nosotros apelamos al derecho de nuestro destino manifiesto...yo supongo que el derecho de un destino manifiesto a extenderse no será admitido a ninguna otra nación, excepto a la universal nación yanqui». Fue lo que dijo el tres de enero de 1846 el senador Robert C. Winthrop del Estado de Massachussets (Prat, 1972).

Los siglos XIX y XX, fueron de gran beneficio para los norteamericanos, que se acostumbraron a manejar las relaciones con Latinoamérica como si se tratara de administrar la huerta familiar. Y es que los intereses en juego han sido muchos: que el petróleo de Venezuela, siempre se dijo, era la primera necesidad de los Estados Unidos. Este recurso finito, ha dictado la política internacional de grandes potencias, facilitado la posesión y derrocamiento de gobiernos, iniciado guerras, ha creado fortunas fabulosas y ha contado entre sus servidores a notables estadistas. Ahora, en 2011, se sabe que hay petróleo en Colombia, Ecuador y en Brasil. Con los minerales ha sucedido lo mismo, pues el desarrollo de la industria en Estados Unidos, se debió a que los países denominados del Tercer Mundo, generalmente actuaron como proveedores de recursos con la afectación de sus condiciones ambientales. A esos recursos del sector primario es a los que hoy se denomina comoditis, como si este término amortiguara los graves daños producidos por su explotación irracional en razón de políticas relacionadas con la producción y el consumo.

La política a escala mundial, y más exactamente los impactos del ejercicio del poder por cuenta de imperios y estados fuertes, siempre ha revestido grados más o menos importantes de complejidad. Desde el rompimiento del statu quo impuesto por la pax romana ${ }^{2}$,

1 La importancia geopolítica de Sudamérica en la estrategia de los Estados Unidos, para mantener la hegemonía global, está intrínsecamente vinculada a su dimensión económica y comercial. Tal vez esa haya sido la razón para que el presidente George W. H. Bush anunciara el 27 de junio de 1990 The Enterprise of the Americas Initiative (EAI), con la intención de instituir una zona de libre comercio, desde Anchorage, en Alaska, hasta la Tierra del Fuego en Chile. El presidente William J. Clinton (1993-2001), que lo sucedió, mantuvo la idea y presentó la propuesta, unilateralmente, a los demás jefes de gobierno, en la Cumbre de las Américas, realizada en Miami, entre el 9 y el 11 de diciembre de 1994, con el nombre de Área de Libre Comercio de las Américas (ALCA).

2 La paz romana (en latín, pax romana), llamada también pax augusta, consistió en un largo periodo de paz impuesto por el Imperio romano a los pueblos por él sometidos. La expresión proviene del hecho que la administración y el sistema legal romanos pacificaron las regiones que anteriormente habían sufrido disputas entre jefes, tribus, reyes o ciudades rivales como, los interminables conflictos entre las ciudades-Estado griegas o tribus galas. 
la desorganización en el orden internacional tiende a ser lo normal. En nuestros días, las crisis y el desorden global se han agudizado en tal proporción que las aproximaciones ortodoxas de la geografía política solo sirven de puntos de partida para abordar estudios de dificultad inusitada. Cierto es que el examen científico del comportamiento del mundo demanda ahora más que nunca del concurso de todas las disciplinas sociales, pero también debe notarse que la contribución de los geógrafos en tal trabajo es de básica importancia. De lo que se trata es de relaciones fundamentalmente espaciales, cuyo estudio es el objeto esencial de la geografía. Y para reafirmar tan legítimo reclamo, si una titularidad histórica fuese menester, debe recordarse que fueron los geógrafos quienes pusieron las bases sobre las cuales se construyó la instrumentación conceptual y teórica de lo que inicialmente se denominó geografía política (Rucinque, 2006). Precisamente, este ensayo aborda temas propios de la geopolítica mostrando cómo, la y las políticas a nivel global y regional, en especial, en Latinoamérica, han sido impactadas por la geografía.

La expresión Latinoamérica nació con Chevallier el canciller de Napoleón III para intervenir militar y políticamente en Iberoamérica en nombre y defensa de la latinité. Luego fueron los yanquis, más tarde la Iglesia católica y por último el marxismo quienes generalizaron el vocablo. Es conveniente recordar entonces que el término América Latina o Latinoamérica se refiere a las regiones del Continente en las que se habla lenguas latinas, es decir, las lenguas romances derivadas del latín como el español, portugués y francés. Precisamente, en Sudamérica, se habla esas tres lenguas.

Durante el siglo XX y lo que va corrido del XXI, la región sudamericana en su conjunto, se ha enfrentado a la globalización en condiciones competitivas desventajosas ${ }^{3}$. El subdesarrollo y la pobreza crecieron a tasas insospechadas ${ }^{4}$ convirtiéndose en sus características relevantes, siendo los grupos sociales más vulnerables los que afrontaron con mayor rudeza el impacto económico negativo. Paradójicamente, las abundantes riquezas naturales no han facilitado el grado de desarrollo que deberían haber alcanzado nuestros pueblos, en algunos casos por factores exógenos y en otros, por la aparición de conflictos internos. Problemas fronterizos no resueltos desde la independencia, dictaduras militares prolongadas, caudillismo político, células guerrilleras ideologizadas desde otros continentes, proceso de aculturación, crimen organizado, narcotráfico y migraciones forzadas, son algunos de los factores de atraso y pérdida de calidad de vida (Beck, 2002). Esta complicada situación política, social y económica, ha convertido a Sudamérica en un importante nicho de observación permanente por parte de quienes imponen el orden mundial y la consideran un baluarte para el futuro de la humanidad, especialmente por asuntos relacionados con la biodiversidad.

En los últimos tiempos, la importancia geopolítica de Sudamérica llama la atención de propios y extraños, incluso, de los estrategas en seguridad de los Estados Unidos, que buscan fuentes de suministro de gas, petróleo, minerales y recursos estratégicos en regiones más estables para mantener el ritmo de producción que garantice el abastecimiento de todos los sectores de la economía en el país más consumidor del planeta. En el siglo XIX el geógrafo Sir Halford J. Mackinder, en su conferencia sobre «The Geographical Pivot of History» en 1904, resaltó que el desarrollo de las vastas potencialidades de Sudamérica

3 La globalización es una etapa histórica vigente en nuestros días que arranco con fuerza de acuerdo con los estudiosos de estos procesos, a partir de los años ochenta del siglo pasado, aunque algunos pensadores la ubican, desde el descubrimiento del continente americano. De modo sintético puede afirmarse que la globalización es la integración del mundo en una unidad económica, social y cultural propiciada por la revolución tecnológica de nuestro tiempo, sobre todo por los avances de los transportes y comunicaciones, que tienen como base la informática y las aplicaciones de la electrónica y la computadora. (Lasso, 2002).

4 Las asimetrías económicas entre países desarrollados y los del tercer mundo, no permiten una competencia que genere mejoramiento de las condiciones de pobreza y marginación. Al contrarió, los pobres aumentan diariamente. 
podía tener «decisive influence» sobre el sistema internacional de poder y fortalecer a los Estados Unidos o, también, a Alemania, en caso de un desafío con éxito, a la Doctrina Monroe que pregonaba el lema «América para los americanos (Mackinder, 1904). Desde entonces, las riquezas naturales marcaron el destino de la región como satisfactores de necesidades foráneas.

Después de su independencia del Imperio español, algunos países latinoamericanos se han agrupado y establecido estrechos nexos con potencias extranjeras en torno a una ideología política. Rusia, China, Corea del Sur, Israel, Libia, Irán, Angola, Sudáfrica, son algunos estados con los que se han establecido exóticos tratados, inicialmente durante la Guerra Fría y luego en plena globalización. El Socialismo del Siglo XXI ha contado con el apoyo de países importantes en el escenario mundial como Irán, Rusia, China y de otros liderados por dictadores como Libia y Cuba. Las relaciones de Venezuela con estos países se han materializado en la compra y donación de armas, entrenamiento a sus fuerzas armadas y proyectos de gran impacto como la construcción de plantas nucleares en Venezuela e instalación y funcionamiento de un satélite chino para propaganda política. La versión de explotación de uranio en Venezuela para exportación a países amigos interesados en la fabricación de armas nucleares, no ha sido descalificada de manera categórica por el actual gobierno y al finalizar el 2011, tomó más fuerza entre las agencias de inteligencia internacionales. En Colombia, se han realizado incautaciones de pequeñas cantidades de uranio, en poder de narcotraficantes de las FARC .

Del Socialismo del Siglo XXI, se argumenta que es un proyecto expansionista que pretende unificar a Latinoamérica, sin que se tenga claridad conceptual al respecto por parte de quienes lo pregonan como la solución a los problemas endémicos. Algunos países entre los que se encuentran Ecuador, Bolivia, Nicaragua, Argentina, Paraguay, Uruguay, Cuba y a partir del 2011 Perú, han mostrado simpatía y respaldo por esta iniciativa liderada por el Teniente Coronel Hugo Chávez. Colombia, se ha opuesto a dicho proyecto y se ha quedado sola en la región convirtiéndose en blanco de ataques de gobiernos simpatizantes del mismo. El presidente Juan Manuel Santos Calderón, quien asumió el poder en agosto de 2010, ha intentado remediar esta situación, logrando avances de forma más no de fondo.

El discurso chavista del Socialismo del Siglo XXI se expandió en el vecindario latinoamericano sin encontrar oposición, salvo la de Colombia. El Tratado de Libre Comercio con Estados Unidos, después de cinco años de fricciones, además de ser un importante hecho económico, obedeció a una maniobra geopolítica que consolida las relaciones económicas, políticas y militares entre el gigante norte americano y su incondicional aliado en Latinoamérica. La materialización de ese proyecto a mediados de octubre de 2011, tendrá efectos económicos y políticos regionales. Así lo reconocen los diferentes análisis que se han hecho en cuanto a las repercusiones que del mismo se derivarán en las exportaciones y finanzas de Colombia; sin duda, habrá numerosas consecuencias geopolíticas a partir de su puesta en marcha.

El nuevo TLC trasciende lo económico y afianza una relación política necesaria entre Colombia y Estados Unidos. No en vano las declaraciones del ex presidente Bush, quien alguna vez calificó el TLC con Colombia como «una medida de seguridad nacional». El presidente Theodore Roosevelt se había referido a la Doctrina Monroe como un corolario para justificar el derecho de intervenir en otros estados latinoamericanos, sobre todo en

5 El gobierno colombiano anunció el hallazgo de un cargamento de 30 kilos de uranio empobrecido que, según las autoridades, había sido adquirido por las autodenominadas Fuerzas Armadas Revolucionarias de Colombia (FARC). Esta información se publico el 27 de marzo de 2008 por la BBC. Mundo.com pero se conocen otras similares en fechas anteriores y posteriores. 
América Central y en El Caribe, en casos de «wrong-doing or impotence» ${ }^{6}$. La estratégica ubicación geográfica de Colombia en la esquina noroccidental de Sudamérica, y sus abundantes recursos naturales, son fundamentales para no perder totalmente la influencia norteamericana en la región.

\section{La geopolítica en el cono sur}

A finales del siglo XIX y hasta la Segunda Guerra Mundial, en las aulas castrenses chilenas la influencia organizacional prusiana se observó, no solo en las formas y apariencias, sino en el armamento adquirido, en la concepción dominante de la guerra terrestre, en la doctrina y por supuesto, en la cultura militar que más tarde se extendería a países vecinos. Chile olvidó su condición marítima y enfatizo en la organización de un típico ejército de infantería, propio para luchar entre las trincheras ${ }^{7}$ La guerra de posiciones de la Primera y Segunda Guerras Mundiales, era el paradigma por parte de los ejércitos asesorados por extranjeros vendedores de armas. Durante la primera mitad del siglo XX se realizaron intensos debates en las escuelas militares chilenas, de los que surgieron dos corrientes que captaron el interés y preferencia de futuros oficiales, que fueron aprendidas por militares de países vecinos y que aún permanecen vigentes a pesar de los cambios sucedidos en el orden mundial, influyendo negativamente en los proyectos nacionales al mantener viva la ideología geopolítica que tuvo su metamorfosis en la geoeconomía actual.

El prusianismo dominante en los cuarteles chilenos, trajo como resultado la enseñanza de conceptos acuñados por la Geopolitk alemana de los años veinte, asegurando una especie de destino manifiesto para Chile que explicaba que la nación se asentaba sobre una geografía definida por la cordillera y el mar, dos realidades inevitables, rodeada de enemigos verdaderos y potenciales (Maldonado et al: 1998). El realismo, doctrina expuesta por Nicolás Maquiavelo, entre otros, consideró en su tiempo que el Estado siempre estaba amenazado y en tal virtud, era necesario contar con un cuerpo armado eficiente para su defensa. Esta doctrina es la que ha facilitado grandes inversiones en armamento y pertrechos para la guerra que han sobrepasado las inversiones en educación y gasto social.

Un buen número de oficiales chilenos, entre 1930 y 1945 adhirieron abierta o discretamente al ideario nazi-fascista y a las concepciones geopolíticas darwinianas de Haushofer y Ratzel, comprometidas con el determinismo geográfico. Esta afirmación se corrobora leyendo el libro Geopolítica de Pinochet, publicado en 1967, en el que, sin originalidad intelectual, el autor se limitó a copiar párrafos completos de autores alemanes nazis o de Golbery de Couto e Silva, geopolítico brasileño de la misma escuela pro-alemana (Hepple, 1986). En ese tiempo, Jomini ${ }^{8}$ predominaba sobre Clausewitz y se imponía entonces una

6 Esta doctrina, sintetizada en el lema «América para los americanos», se había enunciado a finales del siglo XIX, como fundamento ideológico del objetivo estratégico de los Estados Unidos, que consistía en mantener su hegemonía sobre el Hemisferio Occidental, conquistar y asegurar las fuentes de materia prima y los mercados de Sudamérica para sus manufacturas, alejando del sub continente la competencia de Gran Bretaña y de otras potencias industriales de Europa.

$7 \quad$ La geopolítica, disciplina de origen europeo, afincó sus raíces en Chile como en el resto de Latinoamérica, tarde respecto de su aparición, es decir, a mediados del siglo XX, cuando varias escuelas geopolíticas habían mostrado sus alcances y límites en el resto del mundo. La explicación de este fenómeno tiene relación con la presencia de militares alemanes como asesores para la formación de los primeros oficiales del Ejército chileno y luego en otros países de Sudamérica.

8 Antoine-Henri de Jomini (6 de marzo de 1779 - 24 de marzo de 1869) fue un general nacido en Payerne, Suiza, sirvió en el ejército francés y en el ejército imperial ruso. Fue famoso escritor y tratadista de estrategia, analizando el arte de la guerra de la etapa napoleónica y elaborando numerosos postulados teóricos Sus obras tenían un carácter didáctico, y sus teorías se exponían con un vocabulario muy técnico cercano a la geometría, usando términos como «líneas estratégicas, puntos claves y líneas interiores». 
visión geopolítica del territorio asediado por enemigos vecinales ${ }^{9}$. Algunos conflictos fronterizos en Sudamérica se resolvieron militarmente y otros continúan vigentes y en oportunidades sirven para despertar rancios nacionalismos llamando a la guerra, por parte de pintorescos mandatarios en problemas que aún practican el caudillismo para acceder y mantenerse en el poder.

Estas ideas foráneas contribuyeron a la aparición en el Cono Sur de la funesta Doctrina de la Seguridad Nacional, que como todo lo nuestro, procede de los teóricos norteamericanos que en tiempos de la Guerra Fría, argumentaban que el enemigo en nuestros países estaba por dentro ${ }^{10}$. Se referían a los que contradecían los regímenes existentes, personas generalmente de la izquierda que organizaban grupos irregulares a los que se tildó de subversivos y se condenó al exterminio. La DSN tuvo su presentación en Brasil, con el golpe militar de 1964 contra el Gobierno de Joao Gulart y se originó en las aulas de la Escuela Superior de Guerra. En esa primera acción, justificada por la supuesta defensa de la seguridad nacional, las Fuerzas Armadas brasileñas derrocaron el gobierno constitucional e iniciaron una inédita experiencia militar y política, que arrasó con la soberanía popular, se abrogó el ejercicio irrestricto del poder constituyente y aniquiló los derechos individuales y sociales ${ }^{11}$. Al golpe militar en Brasil en el año 1964, se sumaron otros países como Chile en 1973 con el general Augusto Pinochet contra Salvador Allende. Algunos países, entre ellos Venezuela, Bolivia, Uruguay, Paraguay, Ecuador y Perú cayeron en manos de dictaduras que marcaron las décadas del 60 y 70 del siglo XX escribiendo uno de los peores capítulos de la historia en relación con la violación de los derechos humanos (Pittman, 1981). Hubo alianzas entre los regímenes militares para cazar, incluso en las fronteras a los comunistas que eran el objetivo primordial de la DSN.

No es extraño entonces, que tradicionalmente en Sudamérica las fronteras hayan sido concebidas como espacios de seguridad y no como zonas de integración. En la región andina la prioridad desde hace muchos años es fortalecer la presencia militar para prevenir o contener la expansión del conflicto armado colombiano hacia los países vecinos y lograr el control territorial por parte de Colombia, mientras en el Cono Sur, se trata de detener la migración de los vecinos que buscan mejores condiciones de vida. Esta concepción ha dejado de lado, el carácter urgente de ayuda humanitaria en regiones fronterizas y la necesidad de protección de la población civil que huye de la confrontación armada, el hambre y el desempleo (Kaplan, 1983). Al contrario de lo que sucede en otros continentes, las fronteras en Sudamérica, continúan siendo en pleno siglo XXI, espacios de conflicto y permanente tensión. En los últimos años, las fronteras de Colombia con Venezuela y Ecuador especialmente, han sido teatro de operaciones para perseguir a terroristas de las FARC, a los paramilitares, a bandas criminales organizadas y a narcotraficantes internacionales que aprovechando la permisividad de algunos gobiernos, convirtieron esos espacios

9 En Chile la reflexión geopolítica nació en las escuelas castrenses y la hicieron los militares, con todo lo que ello contiene de visiones territoriales y de lecturas parciales y sesgadas. No está demás aclarar que, en el caso de Chile, la comprensión geopolítica llegó primero al Ejército y luego los marinos dieron forma a su propia visión. En la actualidad en las escuelas militares se sigue impartiendo la cátedra de geopolítica y aún se proponen lecturas de las ideas de Pinochet.

10 La doctrina o Teoría de la Seguridad Nacional fue aquella en virtud de la cual se ubicó como valor supremo de la sociedad el orden y el control de los ciudadanos. Para lograr ese orden autoritario y ese contralor, no sólo de las actitudes públicas sino también de la vida personal de los ciudadanos, se consideró que cualquier medio era legítimo. Se asumió la seguridad colectiva o seguridad nacional como valor supremo de una escala de valores que cada persona tiene en su propia vida.

11 Los documentos sobre la DSN tuvieron origen en el primer informe presentado por el presidente Harry S. Truman en 1950, en el que se establecía la doctrina de la contención en el marco de la Guerra Fría. Luego, la ley Goldwater-Nichols en 1986 estableció el Informe Anual al Congreso, donde el Presidente de la República formulaba las bases de la política de la Seguridad Nacional. 
en cultivos de coca, campos de entrenamiento y descanso después de cometer fechorías en territorio colombiano.

\section{El Amazonas y la tesis de Mackinder}

En términos geopolíticos, Sudamérica constituye una isla continental rodeada por los océanos Pacífico y Antártico con 25.432 kilómetros de costas. Es un bloque geográfico que tiene al Amazonas como heartland y comprende casi dos millones de kilómetros cuadrados compartidos por Brasil, Colombia, Ecuador, Venezuela, Bolivia y Perú principalmente. Su difícil acceso motivó a los Estados Unidos a la activación de un dispositivo estratégico para su control; las bases militares de Arauca, Larandia, Tres esquinas, San José del Guaviare, Apiay, Melgar, Puerto Salgar y Barranquilla en Colombia, Iquitos y Nanay en Perú, Mariscal Estigarribia en Paraguay y Curazao, colonia holandesa, a 50 kilómetros de Venezuela. Como soporte ideológico se argumentó la «teoría de la soberanía limitada del Amazonas» asumiendo un tutelaje internacional para el pulmón del mundo, tesis sostenida por la diplomacia sueca y rechazada por Brasil, Venezuela, Argentina y Bolivia. Estas bases forman parte de lo que los Estados Unidos denominan «el escudo defensivo», que suman unas mil en todos los continentes y teóricamente permiten el libre comercio. Lógicamente, este dispositivo militar norteamericano no se ve con buenos ojos por los países sudamericanos a excepción de Colombia que afronta un conflicto interno de 50 años que no ha podido

\section{Bases militares de Estados Unidos para control del hemisferio Occidental}

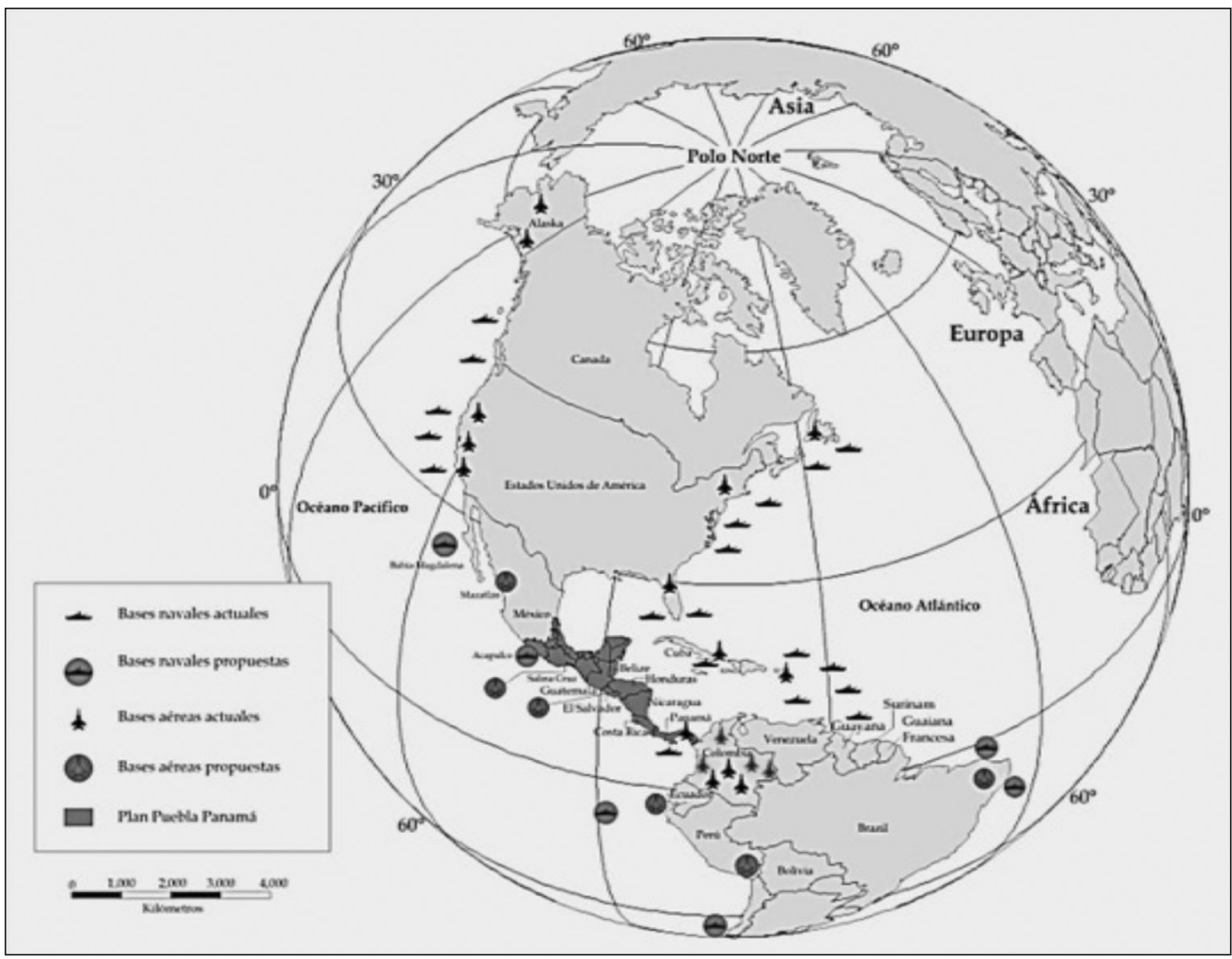

Fuente: Cadena, 2005. 
resolver en términos militares ni políticos, aún con la ayuda de asesores estadounidenses. El Plan Colombia, patrocinado por Estados Unidos, no ha resuelto el problema del narcotráfico ni el de los terroristas de derecha e izquierda.

El libre comercio y la internacionalización de la economía han propiciado la conformación de bloques económicos que buscan el posicionamiento de algunas regiones ${ }^{12}$, estados o empresas transnacionales en lugares privilegiados para promover el intercambio comercial. En el continente americano, como en otras partes del mundo, se están dando estos fenómenos y los recursos naturales, en especial, se constituyen en los principales insumos para proponer nuevos bloques, ajustar y desintegrar otros conformados en épocas anteriores, procurando balancear el poder ${ }^{13}$. No en vano, en los últimos años, la inversión extranjera ha crecido en Sudamérica, en especial para actividades de extracción de recursos y mejoramiento de la agroindustria. El tráfico de drogas genera problemas ambientales y sociales por las grandes ganancias que deja en el mercado internacional su exportación desde los países productores. Este negocio es transnacional y en él participan importantes grupos relacionados con tareas que van desde la producción de precursores químicos, hasta el lavado de activos en paraísos físcales a través de reconocidas entidades financieras (Chislett, 2003).

La aparición de nuevos grupos de poder con intenciones políticas, ha generado reacciones a nivel nacional e internacional con el fin de proteger a la sociedad e impedir la pérdida de valores que afectan incluso las bases de los nacionalismos. A tales extremos ha llegado el interés de algunos grupos criminales por llenar sus arcas con dinero proveniente de negocios ilícitos, que hoy es posible hablar de la guerra contra el narcotráfico y de la influencia geopolítica de este fenómeno. Los más claros ejemplos de este nefasto proceso, son México y Colombia, países en los que las instituciones han sido amenazadas por el poder del dinero. Desde hace algunos años, Sudamérica ha sido la plataforma del narcotráfico en donde las plantaciones de coca y los laboratorios para su procesamiento, reciben apoyo de capitales, tecnología y precursores químicos procedentes del Primer Mundo.

El narcotráfico, aunque no es un nuevo actor geopolítico, es de los más difíciles de combatir por parte de los estados afectados. Su poder corruptor ha penetrado los estamentos oficiales y privados con dinero del ilegal negocio que deteriora la salud de millones de ciudadanos en diferentes partes del mundo, afecta la cultura e incrementa la aparición de fenómenos colaterales, relacionados todos con la pérdida de principios y valores. El dinero fácil ha generado nuevos grupos sociales que se empoderan mediante el empleo de la violencia, afectando a la sociedad. Policías y militares comprometidos con la mafia en no pocos casos, colaborando con grupos a los que supuestamente combaten, se constituyen en los peores enemigos del Estado y de la sociedad que juraron defender ${ }^{14}$. México y

12 El término región es de esencia geográfica en la medida en que designa una porción de espacio caracterizada por una o más realidades definidas por el calificativo añadido a la palabra «región». La región es una porción de espacio o de territorio, es decir, de superficie terrestre.

13 En Latinoamérica, únicamente ocho empresas (BBVA, Santander, Endesa, Iberdrola, Unión Fenosa, Gas Natural, Telefónica y Repsol YPF) monopolizan el $80 \%$ de la inversión española en la región. La facturación de las ocho multinacionales supone aproximadamente el 20\% del PIB del Estado español. Cuatro de ellas, Telefónica, Repsol YPF, Endesa e Iberdrola, están entre las 30 más grandes de la zona, y son líderes en sus respectivos sectores: Repsol YPF es la mayor empresa petrolera de América Latina; Telefónica lidera el sector de telecomunicaciones; Endesa domina el mercado de electricidad y el Santander es el mayor banco de los que operan en la región. Para constatar la importancia de las compañías españolas, basta decir que su participación en el grupo de las mayores transnacionales había ascendido hasta el $14 \%$ en 2005

14 La lucha contra el narcotráfico en Colombia ha sido el pretexto bajo el cual EEUU intenta su penetración militar en Sudamérica, cuyos desarrollos a fines de la década del 90 y en la primera década del 2000 se realizaron bajo la cobertura del Plan Colombia. Si a los tratados y acciones militares oficiales de carácter periódico, se suma la red de relaciones entre las FF.AA latinoamericanas y las FF.AA de Estado Unidos, tendremos el cuadro definitivo de las relaciones de poder en la sombra que se tejen en Sudamérica. 
Colombia han librado una guerra contra las drogas en sus propios territorios, mientras los consumidores del norte son tratados como enfermos dignos de apoyo estatal (Cadena, 1999).

El trópico genera recursos que hoy escasean en otras latitudes y en tal virtud, se ha convertido en un laboratorio de gran interés geopolítico. No en vano las potencias económicas se preocupan en la actualidad por su conservación, pues, contemplan este nicho como una fuente de recursos que ellos no poseen. En una época en que afanosamente se busca reemplazar las tradicionales fuentes de energía que dañan el medio ambiente, solo el trópico está en capacidad de producir materias primas para el biodiesel y otros derivados industriales. Sudamérica tiene una buena parte de su territorio en el trópico, condición que le permite disfrutar de todos los climas y por ende de productos agrícolas hasta el punto de reconocerse que bien pudiera convertirse en despensa mundial de alimentos.

La biodiversidad y los recursos estratégicos endémicos de Sudamérica se encuentran amenazados porque la visión geopolítica imperial ya no consiste solamente en la conquista territorial sino que considera la explotación de los mismos en condiciones favorables al sistema capitalista ${ }^{15}$. Los países beneficiados por la abundancia de los mismos, continúan como proveedores de materias primas. De ahí la relación de los planes estratégicos regionales en los últimos años, algunos vigentes, que combinan lo económico con lo militar y que en el fondo persiguen el control y administración de los recursos para confirmar la hegemonía de un imperio sin competencias ${ }^{16}$ (Cadena, 2005). Los Estados Unidos, fieles al «Destino Manifiesto» y al fundamentalismo basado en la supuesta designación de la Divina Providencia, están dispuestos a cambiar el mapa mundial y a confirmar que la geopolítica tiene caras más amables que las conquistas territoriales o el rompimiento de relaciones internacionales.

A través de la historia, el principal actor de las relaciones internacionales ha sido el Estado, con toda la carga que ello significaba, llámese poder o soberanía, elemento constitutivo del mismo que le permite tomar decisiones. En nuestros días, con el pretexto de la globalización, han surgido nuevos actores que disputan cuotas de poder a los estados sin la aplicación de las viejas normas protocolarias (Cadena, 2009). Diariamente vemos como las empresas multinacionales, mediante la acumulación de grandes capitales mantienen en permanente inseguridad a las economías, especialmente las emergentes. La brecha entre desarrollados y los llamados en vías de desarrollo, es cada día mayor y más difícil de recortar (Painter, 1995). Los problemas se complican cuando en la conformación de bloques, participan los más fuertes económicamente y son ellos los que imponen el orden económico internaciona ${ }^{17}$ generando y manteniendo relaciones de interdependencia. De nada sirve en la región sudamericana la aparición de nuevos grupos de carácter político y económico, si sus decisiones no cuentan a nivel global.

Los principales actores de la geopolítica en siglo XXI son, el terrorismo, las migraciones ilegales, el calentamiento global; la distribución desigual de agua, daños en la capa de ozono;

15 Las preocupaciones de científicos, líderes políticos y propietarios de empresas transnacionales, están fijadas en temas como el cambio climático, superpoblación, subdesarrollo, la globalización como proceso homogenizador de pobreza y violencia, seguridad alimentaria, conflictos de las minorías étnicas, carrera armamentista, el cambiante orden mundial, el analfabetismo y las pandemias.

16 Hegemonismo: es sinónimo de predominio, supremacía, preponderancia y control dominante. Para el caso norteamericano, se entiende como el proceso de expansión y anexión territorial: la ampliación de sus áreas de influencia a través del establecimiento de bases navales, estaciones carboníferas y todo lo que condujese a la extensión de dominio norteamericano.

17 En nuestro tiempo, el crecimiento de la Unión Europea y la configuración de una zona norteamericana de libre comercio, son intenciones de influencia política sobre los asuntos económicos a escala mayor que la del Estado-nación. Los tratados de libre comercio no son tan generosos como pretenden hacernos creer a quienes habitamos en los países llamados del Tercer Mundo. 
desertificación de suelos, contaminación química, y riesgo permanente de la biodiversidad. Frente a este pesimista panorama, los países del Primer Mundo tratan de tomar partido; a los Estados Unidos les preocupa la creciente presencia de China en Sudamérica y pretenden controlar sus recursos minerales y energéticos, como los yacimientos de hierro de Mutum, las reservas de gas natural de Bolivia, Colombia, Venezuela, la Patagonia Argentina y el Acuífero Guaraní, el mayor depósito de agua subterránea del mundo, ubicado en los países que integran el Mercosur (Quagliotti, 2007).

Queda entonces, planteado el interés que para la economía estadounidense ha tenido y tiene la estabilidad política, económica, social y militar de Sudamérica. Dicha estabilidad conlleva seguridad para los inversionistas provenientes de los Estados Unidos y para sus exportaciones dentro del continente y como fuente de recursos vitales para su seguridad y bienestar. El verdadero objetivo estadounidense en Latinoamérica, es el monopolio de un mercado de más de 800 millones de personas y los recursos de agua, gas, petróleo y minerales, la instauración de una moneda única en un mercado, en el que el PIB regional, sumando a los propios Estados Unidos, sería de 13,5 billones de dólares, casi un 30\% mayor al de la Unión Europea ${ }^{18}$ (Rodríguez, 2003). Mackinder aseguró que quien dominara el heartland, dominaría el mundo y en Sudamérica es el Amazonas el territorio geoestratégico de mayor valor.

\section{Sudamérica: una despensa de recursos para el mundo}

Sudamérica es una de las regiones con mayor cantidad de recursos hídricos y fuentes de los mismos. Según el PNUMA (2010), el subcontinente tiene aproximadamente el 27\% del agua dulce a nivel mundial, el 35\% del total de recursos hídricos, el $21 \%$ de las cuencas transfronterizas ${ }^{19}$ y 62 acuíferos ${ }^{20}$. Sin embargo, no todos los países que hacen parte de esta región tienen agua en las mismas proporciones; en Sudamérica, son las zonas con menor cantidad de población las que cuentan con mayor volumen de agua, como las cuencas del Amazonas, el Orinoco y el Magdalena (CEPAL, 2002).

La región sudamericana, poseedora de la mayor biodiversidad sobre el planeta, afronta problemas de inequidad que no se justifican y que impiden su desarrollo en condiciones sustentables en un mundo globalizado en el que teóricamente, la oferta y la demanda deciden los movimientos del mercado con miras a mejorar la calidad de vida de 420 millones de habitantes. Los recursos naturales han pasado a ser en el nuevo siglo, los productos más valiosos para continuar en la carrera del desarrollo tecnológico, supuestamente con la intención de buscar el bien común ${ }^{21}$. En el siglo XXI las actividades extractivas se han

18 La política exterior de los Estados Unidos apuntó tradicionalmente a promover intereses privados específicos (Schoultz, 1998), intereses empresariales, para la promoción de mercados abiertos, libre iniciativa e inversiones extranjeras, objetivos generalmente presentados como de interés para la humanidad. Su estrategia global siempre fue determinada por los intereses y necesidades de su proceso productivo y de su sociedad. La principal preocupación fueron las fuentes de materiales estratégicos, campos de petróleo en Venezuela, minas de estaño en Bolivia, minas de cobre en Chile, uranio en Colombia y recursos existentes en Sudamérica, manteniendo abiertas líneas de acceso, vías de comunicación y transporte, en el Atlántico Sur y en el Caribe (Black, 1986)

19 Las cuencas geográficas son zonas donde el agua cae por precipitación y se escurre a un mismo lugar, ya sea un rio, lago o mar. Cuando la zona que abarca la cuenca se ubica entre dos o más países, se le llama cuenca transfronteriza.

20 Los acuíferos son formaciones geológicas subterráneas que almacenan agua como la que proviene de la lluvia. El agua de los acuíferos es considerada agua potable y se puede usar para el consumo humano.

21 El principal interés de Washington, inter alia, en los estados andinos son las fuentes de energía existentes, y garantizar los suministros de petróleo desde Ecuador y de Colombia, que es actualmente el tercer exportador hacia los Estados Unidos, entre los países de Latinoamérica, detrás de Venezuela y de México. Once de las dieciocho empresas, que extraen petróleo en Colombia, son norteamericanas, cuyas inversiones financian la explotación de un tercio de su territorio, degradando el medio-ambiente. 
convertido en la esperanza de los países subdesarrollados y en el mayor interés de los industrializados. A partir de 2010, las más grandes compañías mineras están invirtiendo en la región gracias a los tratados de libre comercio y a la crisis económica cuya mayor manifestación es el desempleo y la pérdida de poder adquisitivo de los trabajadores.

Los impactos del cambio climático son diversos y en la región tienen relación con la oferta hídrica para los diversos usos, con la producción agropecuaria y con la salud. El abastecimiento de acueductos y la producción agropecuaria se reducen, dificultando los procesos de planificación y la vida diaria de los sudamericanos. El aumento de temperatura genera riesgos de enfermedades tropicales como las infecciones respiratorias agudas, tuberculosis, malaria, fiebre amarilla, dengue, cólera, que han coincidido con la sinergia de otros elementos del medio. La conservación del agua en la región está asociada directamente al cambio en el modelo de ocupación del territorio, de rural a urbano, que junto con otros factores como el cambio climático, generan la crisis actual por el deterioro del agua en el subcontinente $^{22}$. ¿Quién lo creyera? En Sudamérica también se toma agua embotellada, en algunos casos, importada de Francia. ¡Esa es la nueva geopolítica!

La geopolítica de antaño que permitió el florecimiento de grandes imperios, ha tenido una metamorfosis importante hasta convertirse en geoeconomía en la actualidad. El fenómeno de la aculturación facilita las relaciones y negocios internacionales y convierte a los habitantes del planeta en consumidores y no en ciudadanos universales como habría de esperarse en medio de la globalización vigente. Los recursos naturales escasean y la explosión demográfica exige cada día, mayor explotación de los mismos para satisfacer las necesidades de las sociedades más consumistas. Sudamérica es una de las regiones más favorecidas por la naturaleza y en tal virtud, de sus esfuerzos por la racional explotación de los comoditis, depende, el desarrollo sostenible que permita la existencia de futuras generaciones.

\section{Principales actores de la geopolítica sudamericana}

La región sudamericana tiene una población aproximada de 420 millones, que hablan castellano y portugués, mayoritariamente. Diez son las naciones que la conforma políticamente y cuatro enclaves coloniales, las islas Malvinas y Guyana que forman parte del Commonwealth británico, Surinam de Holanda y Guayana francesa. Cuenta con el acuífero Guaraní y con 50.000 kilómetros de vías navegables internas que unen las tres cuencas hídricas: Orinoco, Amazonas y El Plata. Brasil ocupa casi el 50\% del territorio y el otro $50 \%$ de Sudamérica está compuesta por nueve naciones que alcanzan en habitantes, en fuerzas armadas y en PBI al bloque unitario brasileño. Los principales nexos de los dos bloques, el hispano y el lusitano, son la UNASUR y el Consejo de Defensa Suramericano que entró en vigor en 2011 con sede en Buenos Aires.

Pese a la abundancia de agua dulce en Latinoamérica, el acceso sigue siendo insuficiente; al menos 150 millones de habitantes no consumen agua de buena calidad y 250 millones no tienen servicio de saneamiento (UNEP, 2003). Para 2006 solo la mitad de la población rural de la región tenía acceso al servicio de saneamiento, mientras que la población urbana se acercaba al $90 \%$ de cobertura. El 60 por ciento de la biodiversidad mundial está concentrado en la Amazonia y su importancia en términos de explotación y gestión se mide por su aporte a la genética y biología molecular, que llevó al repunte de la industria farmacéutica occidental, después de sufrir en 1980 un gran receso. Pesen a tanta

22 El ciclo hidrológico es el proceso del movimiento continuo del agua en el plantea, las moléculas de agua pueden pasar por diferentes estados, ya sea hielo, vapor o liquido, antes de retornar a su estado inicial. 
riqueza, la región se identifica por la pobreza y los organismos internacionales, poco hacen por resolver el problema. Los eventos más importantes en prospectiva, se describen en el siguiente análisis geopolítico por países.

Colombia, riquezas dilapidadas en la lucha interna. Situado al noroeste del subcontinente, tiene un área continental de 1'141.748 kilómetros y un área marítima de 928.660 kilómetros cuadrados y 48 millones de habitantes. Junto a México es de los países que en Latinoamérica disfruta de dos mares y una variedad de climas que lo convierten en privilegiado en cuanto a recursos naturales. En 2011 Colombia se convirtió en petrolero al extraer un millón de barriles diarios que van todos a los Estados Unidos. A pesar de su conflicto armado, su crecimiento económico alcanzó en los últimos años un $5 \%$ en promedio aunque no se reflejan esas cifras en términos de desarrollo humano. Es uno de los países más desiguales de la región y el conflicto interno consume el mayor presupuesto atendiendo grupos delincuenciales de derecha e izquierda mezclados con el narcotráfico. El conflicto fronterizo colombo venezolano no se ha resuelto y las actividades de los últimos años han intensificado las tensiones. Los colombianos son testigos de la imprudente conducta del presidente Chávez, quien en varias ocasiones ha mencionado la posibilidad de usar las fuerzas armadas venezolanas contra Colombia. A pesar de los apretones de manos y abrazos que se puedan dar en las diferentes cumbres Santos y Chávez, el gobierno colombiano es consciente de la inestabilidad de las relaciones con Venezuela y sus aliados. Graves efectos económicos para los dos países se han originado en las malas relaciones políticas entre sus gobernantes. Al finalizar el 2010, el comercio entre estos dos vecinos prácticamente se redujo a cero después de registrar un balance cercano a los siete mil millones de dólares al año en las exportaciones de Colombia hacia Venezuela.

El pueblo y el gobierno de Colombia, han sido conscientes de la locura que sería trenzarse en una guerra con Venezuela, la cual, hipotéticamente no duraría mucho por la superioridad militar de los primeros. No obstante, saben que deben fortalecer muchos frentes; la formalización de la relación con Estados Unidos es uno de ellos. Los intereses geopolíticos de Estados Unidos en Colombia ahora son mayores; se puede decir que si antes había un trato preferencial entre los dos países, ahora hay una imprescindible necesidad que se refleja también en la defensa del territorio colombiano, frente a las amenazas del proyecto expansionista bolivariano, lo que explica el crecimiento logarítmico de la fuerzas militares y de policía en el país andino que ya alcanzan un pie de fuerza cercano a los 480 mil hombres. Lo que se denomina en términos estratégicos, poder relativo de combate, es muy superior a favor de Colombia con respecto a la mayoría de países en la región ${ }^{23}$. Como si los problemas con Venezuela fueran pocos, Nicaragua, un pequeño país centroamericano, ha planteado a Colombia un litigio jurídico internacional, reclamando la Isla de San Andrés, ubicada en El Caribe, amenazando incluso, con incursiones armadas si la situación no se resuelve a su favor, contando con el apoyo irrestricto y público del gobierno de Venezuela. Por ahora, el asunto se encuentra para resolución en la Corte de la Haya. En promedio, Colombia gasta el 4,5\% en defensa aunque en el año 2008 gastó el 6,3\% del PIB. Su policía está militarizada y sobrepasa los 130 mil efectivos. Su Armada es pequeña para el cuidado de dos mares por lo que frecuentemente se presentan incursiones de flotas pesqueras extranjeras en búsqueda de recursos ictiológicos. Colombia, país de inmejorables condiciones económicas, no ha salido de un conflicto fratricida que ha tenido apoyo de algunos vecinos y a pesar

23 El poder relativo de combate de manera general, es la sumatoria de los recursos humanos y técnicos con los que cuenta un país para resolver asuntos de carácter estratégico. La experiencia en combate, la preparación de los mandos y el entrenamiento de las tropas, al igual que las dotaciones y pertrechos, juegan papel importante en la definición del objetivo de la guerra que por doctrina no es otro que la victoria. 
de contar con excelente recurso humano, ha permitido que la corrupción de su clase dirigente, amplié la brecha entre ricos y pobres.

Venezuela, la economía crece y el desarrollo no se ve. Con una superficie continental e insular de 916.445 Kilómetros cuadrados y una población que llegó recientemente a los 28 millones de habitantes, ha tenido una economía de mercado con énfasis en las exportaciones. Su principal actividad económica es la explotación y refinación de petróleo para la exportación y consumo interno. Clasificada como la quinta economía de Latinoamérica, después de Brasil, México, Argentina y Colombia, dedica esfuerzos al procesamiento de petróleo por parte de la industria estatal Petróleos de Venezuela (PDVSA). En 1914; se inició la construcción de la primera refinería para procesar gasolina, queroseno y gasóleo y a partir de 1922 inició la explotación a gran escala; mediante iniciativa y participación de Venezuela dentro del mercado mundial se fundó la Organización de Países Exportadores de Petróleo (OPEP).

La renta per cápita de Venezuela a principios de siglo XX era notablemente inferior a la de los países del Cono Sur, Argentina, Chile, Uruguay, e incluso era inferior a la de países geográficamente comparables como Perú y Colombia. A partir de 1925 y debido a la explotación de petróleo a gran escala, Venezuela superó la renta de Perú y Colombia, y a partir de 1945 experimentó un vertiginoso crecimiento convirtiéndose en el país latinoamericano de mayor renta per cápita, aunque a partir de 1980, esta había empezado a disminuir. En el tercer trimestre de 2011, Venezuela registró según cifras del Banco Central un crecimiento superior al 4,2\%. Todos los sectores de la economía sufrieron un alza debido a la oferta y demanda del país. Las inversiones crecieron 1\% en 2011 acumulando dos años seguidos de caída. Venezuela sigue teniendo la inflación más alta del continente; los precios de los bienes y servicios subieron $27,6 \%$, un poco más que en 2010 cuando fue $27,2 \%$. Los productos que más encarecieron fueron los alimentos con una inflación de $33,9 \%$. La inversión extranjera ha desaparecido por las continuas nacionalizaciones de empresas privadas por orden expresa del presidente Chávez. La pequeña industria de bienes de consumo ha sido desmantelada y en la práctica no existe, la calidad de vida de los venezolanos ha caído y la migración a Estados Unidos y Colombia, creció, especialmente por parte de personas con suficientes recursos económicos que no están de acuerdo con el proyecto bolivariano.

Las exportaciones venezolanas al exterior, principalmente petróleo, subieron 42,8\% en 2011, luego de una drástica caída en 2010 de 12,9\%. En total, Venezuela exportó mercancías por un total de 93.896 millones de dólares. La compra de bienes desde otros países se incrementó 18\%, al cerrar el año 2011 con un monto de 45.615 millones de dólares. Las reservas internacionales del país cerraron en 29.899 millones de dólares. Al último día del año 2011, la cifra fue de 433 millones de dólares, menor al cierre de 2010. Sin embargo, la bonanza petrolera no ha llegado al pueblo y Venezuela continúa siendo del Tercer Mundo con problemas económicos, sociales y políticos que se agudizan día a día. Las mayores inversiones en los últimos 13 años se han dado en el sector defensa, adquiriendo compromisos con Rusia, China, e Irán.

La Fuerza Armada Nacional de Venezuela está compuesta por 155,000 efectivos, sin contabilizar las reservas y distribuidas así: el Ejército Nacional con 93.000 efectivos; 60\% del total; la Guardia Nacional con 23.250; 15\%; la Armada Nacional con 15,500; 10\%; y la Aviación Militar con 23.250; 15\%. La Milicia Nacional o reserva tiene 787.500 efectivos «en buen estado para la guerra». Venezuela ocupa el tercer lugar en la relación de efectivos militares por cada 10 mil habitantes para Sudamérica (Global, 2011). Oficialmente se ha dicho que las milicias están armadas y se especula con el número de fusiles que podrían sumar entre 200 mil y 400 mil. Chávez, pese a su cáncer terminal, aspira a un tercer periodo 
presidencial y el panorama político es complicado con un gobierno dispuesto a repetir los periodos de algunos antecesores que permanecieron hasta 20 años en el poder, una oposición decidida a poner fin al proceso bolivariano y buena parte de la población civil armada y entrenada por expertos. Al iniciar el 2012, se produjo el primer fallo internacional en contra de Venezuela por demandas de una compañía petrolera inglesa, su cónsul general en Miami Livia Acosta, fue expulsada por el gobierno de Estados Unidos y el presidente de Irán Mahmud Ahmadineyad, visitó Caracas para corroborar varios tratados comerciales y militares. ¡Lo más parecido a un polvorín!

Brasil, una potencia emergente. Con una superficie estimada en más de 8,5 millones de kilómetros cuadrados, ocupa el quinto lugar a nivel mundial en territorio, sólo superado por Rusia, Canadá, China y Estados Unidos y tiene fronteras con todos los países de Sudamérica, exceptuando a Chile y Ecuador, con una población de 195 millones. Entre 2007 y 2008, Brasil subió dos puestos en el ranking de producción científica, alcanzando el décimo segundo lugar: pasó de 20 mil a 35 mil artículos publicados en revistas científicas indexadas, superando en el ranking a Rusia y a los Países Bajos, aportando el 2,14\% de los artículos de 183 países. Sus universidades oficiales se clasifican entre las mejores de Latinoamérica e incluso del mundo, pues la inversión en investigación ha sido preocupación importante de los últimos gobiernos. Es el único país latinoamericano integrante del grupo BRICS, compuesto además por Rusia, India, China y Sudáfrica y su crecimiento económico hace prever que pronto será la quinta economía mundial. El eficiente manejo económico ha logrado desarrollo humano mejorando las condiciones de 20 millones de habitantes en los últimos ocho años pero eso no garantiza que la región sudamericana se haga partícipe de esos logros nacionales brasileños.

Las Fuerzas Armadas de Brasil están constituidas oficialmente por el Ejército, la Marina, la Fuerza Aérea y la Policía Militar de Estado que opera como una fuerza auxiliar del Ejército. Las Fuerzas Armadas brasileñas son las más grandes de Latinoamérica y forman parte del Ministerio de Defensa. La Fuerza Aérea del Brasil es la más importante de la región, con unos 700 aviones tripulados en servicio, y aproximadamente 70.000 empleados en servicio activo, de los cuales, unos 9000 son civiles especialistas. La Marina del Brasil es responsable de las operaciones navales y de vigilar sus aguas territoriales. Es la más antigua de las Fuerzas Armadas brasileñas y la más grande de Latinoamérica, con un portaaviones de 27.307 toneladas, el NAE São Paulo, que formó parte de la Marina francesa, unas fragatas de construcción americana y británica, algunas corbetas de construcción nacional, submarinos costeros y muchos aviones de patrullaje sobre las costas. Brasil compró en 2010 el primer submarino nuclear a Francia y espera producir ocho submarinos idénticos en los próximos cinco años. El Ejército brasileño es responsable de las operaciones militares terrestres, con un pie de fuerza aproximado de 270.000 soldados. Su presupuesto militar fue de 10.000 millones de dólares en el 2010, similar al de Colombia, contra 3.200 millones del argentino. La mayor hipótesis de conflicto que se plantea el Ejército de Brasil es contra una superpotencia en terreno boscoso, de ahí que la preparación y entrenamiento se oriente a las operaciones de selva.

La industria militar brasileña ha logrado grandes avances en los últimos años y por venta de aviones, vehículos de combate, tanques y fragatas, ha recibido recursos importantes para mejorar su situación económica, a la vez que le permite mantener relaciones internacionales fluidas con otros estados. El pensamiento geopolítico brasileño he tenido permanente interés en una salida por el Pacífico y no es atrevido pensar que en esta nueva etapa, el proyecto pueda materializarse a través de Perú o Ecuador, incluso de Colombia. En el corto plazo sabremos que estas Fuerzas Armadas participan en la defensa de los recursos de la Amazonia. 
Argentina, una economía sin brújula. La superficie continental es de 2'791.810 kilómetros cuadrados con una población de 41 millones de habitantes de acuerdo al censo de 2010 . Conocida en 1910 como la undécima economía del mundo retrocedió al lugar número veinte un siglo después y su Armada, la segunda del mundo en 1890 pasó a no existir. El motor de su economía ha sido el agro, principalmente la producción de cereales y oleaginosas, que constituyen el primer renglón de exportación, sin embargo, el cambio climático está afectando la producción de manera sistemática. También su industria liviana ha logrado un buen desarrollo. La estructura de las exportaciones argentinas está equilibrada pues su composición es: combustibles $12 \%$, industria $31 \%$, agricultura $34 \%$, comoditis $23 \%$. La ganadería, materia prima para la industria de la carne, es un sector de gran importancia, con 60 millones de cabezas, aunque en los últimos años, está disminuyendo.

Históricamente la industria minera argentina ha sido incipiente, pero se ha activado en la última década la extracción de metalíferos como el oro, plata, zinc, manganeso, uranio, cobre, y azufre. Estos recursos se concentran en las provincias cordilleranas a lo largo de 4500 kilómetros. Las exportaciones argentinas de minerales pasaron de 200 millones de dólares en 1996 a 1200 millones en 2004, algo más del 3\%. Lo grave es que la minería, que no produce ningún desarrollo posterior por ser una actividad meramente extractiva, alcanzó en la primera década del siglo XXI porcentajes de exportación muy altos. La investigación en el campo del desarrollo nuclear se ha realizado en forma continua desde 1950 y se han logrado algunos avances.

Los militares argentinos fueron muy influyentes en la política del país y a menudo interrumpieron los gobiernos democráticos. Los Golpes de estado militares derrocaron a gobiernos elegidos en 1930, 1943, 1955, 1962, 1966 y 1976. La dictadura implantada en 1976 denominada Proceso de Reorganización Nacional por los golpistas, que se mantuvo hasta 1983, justificó detenciones arbitrarias, torturas, ejecuciones, desaparición forzada, secuestro de niños con el argumento de enfrentar al terrorismo. Los dos últimos gobiernos han ordenado investigaciones para castigar a los responsables, generando polarización entre sectores de derecha que ven en esas acciones, una retaliación política atemporal de los gobiernos de izquierda en el poder. Se reabrieron casos de la justicia cerrados en otros gobiernos y se han puesto de moda, condenas a cadena perpetua contra los militares de las dictaduras. El desgaste de los gobiernos del matrimonio Kishner en asuntos ideológicos, ha traído serios problemas a la economía que se notan en la caída de la calidad de vida de los argentinos. La actual presidenta Cristina Kishner, es aliada incondicional del proceso bolivariano de Hugo Chávez.

En 1978, el rechazo argentino al Laudo Arbitral de 1977 originó un conflicto con Chile por las islas Picton, Nueva y Lennox que llevó a estos países al borde de la guerra. La Junta Militar que de facto gobernaba Argentina planeó y ejecutó la Operación Soberanía y ocupó las islas. El conflicto fue resuelto por mediación del papa Juan Pablo II que condujo al Tratado de Paz y Amistad de 1984. En 1982, al intentar reclamar las Islas Malvinas a Inglaterra, Argentina sufrió su peor humillación militar y la dictadura cayó por reclamos de la ciudadanía. Durante los gobiernos de Carlos Menem y Fernando de la Rúa las relaciones con Chile mejoraron con la solución de casi todos los problemas limítrofes. Luego del retorno de la democracia en 1983, las Fuerzas Armadas de Argentina se han reducido en efectivos y presupuesto e iniciaron una política de cooperación y amistad con sus homólogas de Brasil y Chile.

A partir del año 2000 se produjeron algunos cambios significativos: Se negó a los Estados Unidos la inmunidad de sus Fuerzas Armadas en el territorio argentino y se ampliaron las distancias con Norteamérica en materia internacional, en oposición a la política intervencionista. Sin embargo, Argentina mantiene relaciones de cooperación militar con 
los Estados Unidos y en menor escala con Israel, Alemania, Francia, España e Italia. En 2011 Argentina inició la compra por primera vez en su historia de armamento procedente de Rusia y China. Dentro de Sudamérica sus mayores aliados militares son Brasil y Venezuela. El gasto en defensa de Argentina, en 2010 era, como desde el regreso de la democracia en 1983, 3200 millones de dólares, que representa el 1,07\% de su PIB, por debajo del 1,74\% promedio de Sudamérica.

Chile, crecimiento económico con desarrollo humano. Ubicado en el hemisferio sur con una extensión de 755.915 kilómetros cuadrados y costas del territorio continental e islas adyacentes que suman 83.850 kilómetros. La población estimada a junio de 2011 alcanzó 18 millones de habitantes. La economía de Chile, considerada actualmente la más desarrollada de la región, alcanzó un índice de desarrollo humano (IDH) de 0,805 en 2011, el más alto de Latinoamérica. Según estimaciones del FMI, Chile alcanzará un PIB per cápita de poco más de 21000 dólares en 2016. En mayo de 2010, Chile se convirtió en el primer miembro pleno de la OCDE en Sudamérica y segundo en Latinoamérica, después de México, en reconocimiento a los avances económicos de las últimas décadas, desarrollo social y fuerte reestructuración institucional, que ha llevado al país a ubicarse entre los treinta miembros de esta organización, que agrupa a las principales economías industrializadas del mundo.

Chile posee una economía diversificada y competitiva, destacando el mercado minorista en el que sobresalen empresas chilenas con inversiones en distintos países de Sudamérica. Además, tiene uno de los sistemas bancarios más estables y desarrollados de la región. Su principal sector económico es la minería, principalmente el cobre, del cual es uno de los mayores productores del mundo. Los recursos forestales se localizan en la mitad sur de su territorio. Los recursos del mar son de gran importancia, por la extensión de la zona económica exclusiva. Además, en la Zona Austral de Chile hay yacimientos de petróleo confirmados.

En los últimos años la economía chilena ha mostrado una tasa de crecimiento estable, promediando el 4,5\%, el cual fue frenado sólo por la crisis económica. Chile pretende convertirse en la plataforma de inversiones para muchas empresas, siendo este país el punto de partida para ingresar a otras economías sudamericanas. La economía de Chile se caracteriza por su desarrollo orientado a las exportaciones. El perfil exportador ha estado compuesto en los últimos tiempos por un $45 \%$ de carácter industrial, $45 \%$ minero y un $10 \%$ de exportaciones agrícolas. Estas cifras se modifican coyunturalmente debido a las variaciones del precio del cobre, del cual Chile depende en un $35 \%$ de las ventas al exterior. El sector industrial sobresale por la exportación de celulosa, madera, metanol y agroalimentarios. Las industrias forestal, del mueble, del salmón y del vino, de reconocido prestigio internacional, han adquirido gran importancia en la última década. Puede afirmarse que Chile es el país sudamericano que menos problemas confronta y en el que la gente vive mejor. Los dos últimos gobiernos, el de Michelle Bachelet y el de Sebastián Piñera, han tomado las cosas con seriedad, dando importancia al desarrollo humano sobre el crecimiento económico.

Ecuador, eterna pobreza con nuevos caudillismos. Con costas sobre el Pacífico, un área de 256.370 kilómetros cuadrados y una población de 15 millones, la economía de Ecuador es la octava de Latinoamérica que entre 2000 y 2006 experimentó un crecimiento promedio del 4,6\%. El PIB se duplicó entre 1999 y el 2007, alcanzando 65.490 millones de dólares. Ecuador no tiene un buen nivel de producción y los recursos naturales no son abundantes, en materia de hidrocarburos existe cierta estabilidad; la economía ecuatoriana se sostiene por la venta de servicios al exterior. El $20 \%$ de su población ha emigrado en búsqueda de oportunidades, especialmente, a España y Colombia. El petróleo representa $40 \%$ de las exportaciones y contribuye a mantener una balanza comercial positiva. Desde finales de los años 60, la explotación de petróleo creció y sus reservas se calculan en 4.036 millones 
de barriles. La balanza comercial petrolera generó una cifra positiva de 3.295 millones en el 2008; mientras la no petrolera fue negativa por un monto de 2.842 millones de dólares.

Ecuador ha negociado tratados bilaterales con otros países, además de pertenecer a la Comunidad Andina de Naciones, y ser miembro asociado de Mercosur. En abril de 2007 Ecuador pagó por completo su deuda con el FMI terminando así una etapa de intervencionismo de este Organismo en el país. En el 2007, se creó la Unión de Naciones Sudamericanas (UNASUR), con sede en Quito, cuyo primer Secretario General fue el ex presidente ecuatoriano Rodrigo Borja Cevallos. También se inició la creación del Banco del Sur, junto con otros seis países sudamericanos, propuesta de Hugo Chávez realizada en 2004, que nació muerta pues su capital inicial se fijó la insignificante suma de 7.000 millones de dólares, cuando el banco del Brasil tiene activos por 407.000 millones y el banco Itaú de Sao Paulo por 350.000 millones de dólares. Ecuador había iniciado negociaciones para un Tratado de Libre Comercio con Estados Unidos, pero con la elección del presidente Correa, estas gestiones fueron suspendidas. La defensa del país está a cargo de las Fuerzas Armadas del Ecuador que cuentan con cerca de 85. 518 efectivos militares activos y 118 000 reservistas organizados así: Ejército 73.260, Armada 7258 y 24 buques y la Fuerza Aérea, 5000 efectivos. Armamento comprado a Inglaterra, Francia, Estados Unidos, Israel y Brasil. Con un alto porcentaje de población indígena mayormente pobre, tiene grandes problemas de infraestructura y de desarrollo humano no resueltos. Al finalizar el siglo XX e iniciar el XXI la inestabilidad política se caracterizó por la llegada al poder de personajes folclóricos que polarizaron la población y agravaron los problemas sociales. Los indígenas se empoderaron y cambiaron cuatro presidentes mediante marchas y paros. Este es el único país del mundo en el que el presidente sale a pedirle a los policías que lo maten y luego los denuncia por intento de asesinato. Comenzando el 2012 el presidente Correa afronta serios problemas por medidas de fuerza tomadas en contra de la prensa nacional, mientras su pueblo permanece sumido en el subdesarrollo.

Perú, crecimiento inusitado. Situado en la parte centro-occidental de Sudamérica, conformado por un territorio continental de 1'285.215 Kilómetros cuadrados. El Mar Peruano o Mar de Grau es la parte del Océano Pacífico demarcado a lo largo de la costa peruana con una extensión de 3.079 kilómetros. Su gran riqueza ictiológica es resultante de las corrientes marinas de Humboldt y del Niño. La población de la República del Perú de acuerdo al Censo de 2007 ascendió a 30 millones de habitantes. En los dos últimos gobiernos su crecimiento económico ha sido uno de los más altos de la región alcanzando promedio hasta de 6,5\%. Es un país agrícola como todos los de Sudamérica pero está progresando en pequeña y mediana industria.

Bolivia, de los más pobres del mundo. Con una superficie de 1.098 .581 kilómetros cuadrados y sin salida al mar, es considerada el centro de Sudamérica, tiene 10.027.643 de habitantes. Enfrentó en una guerra a Chile perdiendo su salida al Pacífico y luego a Paraguay en la llamada Guerra del Chaco que causo una terrible perdida material y en vidas humanas. En términos geopolíticos se considera un Estado tapón y su pobreza lo ubica entre los menos desarrollados del mundo. Sin embargo, sus actuales dirigentes políticos se encuentran enfrascados en discusiones bizantinas invirtiendo en armas y apoyando el socialismo del siglo XXI. Pese a su riqueza en petróleo, gas y otros minerales, el país se derrumba ante la indolencia de su clase política que defiende sus propios intereses.

Paraguay, experiencia en la guerra y pobreza endémica. Con una superficie de 406.752 kilómetros cuadrados, carece de acceso al mar, su economía es agrícola y pecuaria. Otro Estado tapón que vive de actividades primarias y del apoyo de sus vecinos Brasil y Argentina. Su población alcanza los 4’995.237 habitantes. Luego de dictaduras militares y guerras con vecinos, son pocos los avances económicos y sociales. Fernando Lugo, un ex 
obispo que mantiene al país de escándalo en escándalo por situaciones personales, es su actual presidente.

Uruguay, del militarismo a la democracia sin rumbo. País oriental del Cono Sur con una superficie de 176.215 kilómetros cuadrados y 3’241.003 habitantes. Con continuas crisis el país se caracteriza por falta de políticas que determinen un proyecto de nación. Su actual presidente José Mujica, en el discurso de posesión, prometió la eliminación de la indigencia y la reducción de la pobreza en un 50\%. Denominada la Suiza de América por los altos niveles de vida a principios del siglo XX, su situación cambió abruptamente por malos manejos políticos, dictaduras militares y aparición de grupos delincuenciales y terroristas que se extendieron por el subcontinente.

\section{Integración económica sudamericana}

El principal bloque comercial de la región es la Unión de Naciones del Sur (UNASUR) conformada por el Mercado Común del Sur y la Comunidad Andina de Naciones, que intenta la integración económica a nivel continental a través de la Asociación Latinoamericana de integración (ALADI) y del Sistema Económico Latinoamericano y del Caribe (SELA). Bolivia, Cuba, Nicaragua y Venezuela tienen su propio bloque, llamado Alternativa Bolivariana para América Latina y el Caribe (ALBA). El bloque predominante es el Mercosur, integrado por Argentina, Brasil, Paraguay, Uruguay, con Bolivia, Chile, Colombia y Perú como miembros asociados; Bolivia, Colombia, Ecuador y Perú conforman la CAN, a la que pertenecen los países vecinos como miembros asociados y recientemente, Chile, Colombia, México y Perú firmaron el Acuerdo del Pacífico con el objetivo de conquistar el mercado asiático. El G3 está conformado por México, Colombia y Venezuela pero en realidad el último país se ha desvinculado casi totalmente de los compromisos adquiridos por asuntos de carácter ideológico. Fuera del ámbito continental, Argentina, Brasil y México son los únicos países latinoamericanos que forman parte del Grupo de los 20 países industrializados (G20); mientras que Chile, México y Perú forman parte del Foro de Cooperación Económica Asia-Pacífico (APEC). Chile y México son los únicos que forman parte de la Organización para la Cooperación y el Desarrollo Económico (OCDE).

La Comunidad de Estados Latinoamericanos y Caribeños (CELAC), es un organismo intergubernamental de ámbito regional, heredero del Grupo de Rio y la Cumbre de América Latina y del Caribe (CALC) que promueve la integración y desarrollo de los países latinoamericanos. Su creación fue en 2010, en la ciudad Playa del Carmen, México. La reunión tuvo como objetivo, profundizar la integración en un marco de «solidaridad, cooperación, complementariedad y concertación política» de los países latinoamericanos y caribeños. La Primera Cumbre de la CELAC, para su constitución definitiva, tuvo lugar en Caracas, los días dos y tres de diciembre de 2011. En la declaración de 33 jefes de Gobierno asistentes, constituyeron la Comunidad de Estados Latinoamericanos y Caribeños como «espacio regional propio que una a todos los estados». Los mandatarios presentes en la cumbre manifestaron esperanza que la consolidación de la CELAC facilite la liberación de Latinoamérica de la tutela tradicional de Estados Unidos y Europa posibilitando el avance en la integración de los pueblos, la resolución de sus conflictos así como la promoción del desarrollo económico.

En la reunión de Caracas se promovió que el nuevo organismo, que excluye a los Estados Unidos y Canadá, quede perfilado tras el proceso de constitución iniciado en el seno del Grupo de Río. La próxima reunión se programó para el 2012 en Chile. La población total de los países integrados en la CELAC se aproxima a los 550 millones de habitantes y el territorio alcanza una extensión de más de 20 millones de kilómetros cuadrados. Algunos 
críticos de la CELAC la ven como el contrapeso de la OEA, entidad de la que el presidente Chávez manifiesta constantemente, «es un peón de los Estados Unidos y en nada coadyuva a la solución de los problemas en el continente americano».

\section{Conclusiones}

La región sudamericana necesita una verdadera integración, que permita además de crecimiento económico, el desarrollo humano mediante la eliminación de la pobreza, la desigualdad y la violencia en todas sus manifestaciones.»Formar en América la más grande nación del mundo por su extensión y riquezas que por su libertad y gloria», proclamaba el libertador Bolívar en 1815 (Pabón, 1997). Para él, era claro, que sólo la unión cultural y de raza, haría posible esa gran nación que llamó la Gran Colombia y que propuso en la Carta de Jamaica. La actual polarización entre gobiernos de izquierda y de derecha, influenciados por ideologías foráneas con interese propios, imposibilita en la práctica la integración y condena a la región a la condición de proveedora de comoditis. La llegada al poder de dirigentes políticos incapaces, algunos sin estudios de secundaria siquiera, está retardando el avance de los pueblos que merecen mejor suerte.

El Área de Libre Comercio de las Américas (ALCA) es el corolario de la aplicación de políticas capitalistas globales que en Estados Unidos intuyeron los neoliberales y cuyo objetivo es la apropiación jurídica de todo el hemisferio occidental a través de una integración que sólo proporciona ventajas y beneficios a los grandes capitales norteamericanos sin importar que el hambre, la pobreza, el analfabetismo y la violencia, continúen afectando a los pobladores de Sudamérica. Lo más grave es la práctica y avance de la aculturación, fenómeno sociológico que coadyuva en los planes transnacionales de transformar a los sudamericanos en consumidores de los productos del norte a través de nuevas costumbres y prácticas sociales.

Las intenciones expansionistas de los Estados Unidos fundamentadas en el «Destino Manifiesto» ${ }^{24}$, hoy reaparecen con claridad por asuntos más importantes que el mismo territorio; los recursos naturales y los mercados internacionales, constituyen el mayor empeño geopolítico para la existencia de grandes potencias. La militarización del espacio, es crucial para la seguridad nacional norteamericana, y su regulación pertenece al dispositivo estratégico en desarrollo. Los gobernantes de Sudamérica, en su conjunto deberían tener clara idea al respecto y actuar en consecuencia, pero mientras subsista la ignorancia política de sus pueblos y permitan el ascenso al poder de caudillos prepotentes, desconocedores de la realidad y sin el bagaje técnico e intelectual para manejar los problemas internos y generar proyectos de nación, la situación seguirá empeorando.

La defensa del territorio nacional siempre ha sido una prioridad de las Fuerzas Armadas de cualquier Estado-nación. Sin embargo, los Estados Unidos, por su poder, sus carencias, sus necesidades en energía, minerales, capitales financieros, recursos humanos, después de la Segunda Guerra Mundial, incrementaron las intervenciones y compromisos internacionales, y eso determinó una segunda prioridad, que no es otra que la movilización de su población y creación de escudos defensivos en lugares estratégicos. La reactivación de la IV Flota y sus recientes incursiones en el Pacífico, así como las operaciones de la V Flota en Oriente Medio, son muestras fehacientes del interés de revivir la geopolítica de principios del siglo XIX, aplicando la Doctrina de Mahan en relación con el dominio de los mares.

24 Los Estados Unidos desde 1846 tienen la creencia convertida en doctrina que el de ellos es un derecho amparado en el destino manifiesto a extenderse sobre el continente americano. Con ese pretexto emprendieron campañas de despojo territorial en el continente, instalando bases militares que en unos casos han sido reclamadas y en otros, permanecen como parte de su escudo de seguridad. 
Con el fin de proteger los recursos del Atlántico sur, no sería raro, la conformación de una fuerza naval entre Brasil y Argentina para garantizar la seguridad del mar y del extenso litoral. Evitar el saqueo que se está produciendo en el Atlántico sur es asunto de soberanía y en la lucha por los recursos, un conflicto naval no debe descartarse. El pacífico sur debe ser controlado por Chile que posee una importante fuerza naval con el apoyo de Colombia y Perú. En la región sudamericana se destacan en primer lugar el poderío militar colombiano de tierra y chileno de mar. Se ha producido desde la asunción de Hugo Chávez un rearme de Venezuela, fundamentalmente ruso. Fusiles automáticos para guerra de baja intensidad, aviones y helicópteros. En cambio Argentina desde la derrota de la guerra de Malvinas en 1982 ha adoptado la tesis de inexistencia de conflictos internacionales y la de diplomacia desarmada. En cuanto a Uruguay, Paraguay, Bolivia, Perú, Ecuador carecen de peso específico en la materia. A no dudarlo, la potencia militar sudamericana es Brasil y seguramente en el futuro sabremos de su contribución al desarrollo nacional.

\section{Referencias bibliográficas}

BECK, U. (2002): La Sociedad del riesgo Global. Sociología y Política. Traducción de Jesús Alborés Rey. Siglo XXI editores. Madrid, 304 pp.

BLACK, J. K. (1986): Sentinels of Empire. The United States and Latin American Militarism. Greenwoodpress, N.York, $446 \mathrm{pp}$.

CADENA MONTENEGRO, J. L. (1999): Propuesta de evaluación de la eficiencia del Ejército de Colombia. Tesis de grado para obtener el título de Magíster en Ciencia Política. Universidad de Los Andes. Bogotá, 228 pp.

CADENA MONTENEGRO, J. L. (2002): La geografía y el poder. Territorialización del poder en Colombia. De Marquetalia al Caguán. Tesis de grado para optar al título de Magíster en Geografía. Universidad Pedagógica Tecnológica de Colombia-IGAC. Bogotá, 336 pp.

CADENA MONTENEGRO, J. L. (2005): El Plan Puebla Panamá: una revisión geopolítica. Tesis de grado para optar al título de Doctor en Geografía. UNAM, México, 286 pp.

CADENA MONTENEGRO, J. L. (2009): «200 años de independencia de Latinoamérica y su evolución geopolítica: una visión desde Sudamérica», en Revista de Relaciones Internacionales, Estrategia y Seguridad. UMNG No. 4-1. Bogotá, pp. 91-111.

CARDONA, D. (2005): «¿Tiene futuro la Comunidad Suramericana de Naciones?», en Foreign Affairs (edición en español), vol. 5, pp. 84-92.

CEPAL (2002): La sostenibilidad del desarrollo en América Latina y El Caribe: desafíos y oportunidades. Naciones Unidas. México, 232 pp.

CHISLETT, W. (2003): «La inversión española directa en América Latina: retos y oportunidades», Real Instituto Elcano, http://www.slideshare.net/gueste984e2b/w-chislett-las-multinacionalesespañolas (consultado el 08 de noviembre de 2011). Madrid.

GLOBAL FIREPOWER.COM (2011): http://www.globalfirepower.com/country-military-strengthdetail.asp? country_id=Venezuela (consultado el 06 de noviembre de 2011)

HEPPLE, L. W. (1986): «Geopolítica, generales y el estado en Brasil», Publicación Trimestral de Geografía Política No. 48, pp 79 -90.

JAGUARIBE, H. (2005): «El proyecto sudamericano», en Foreign Affairs (edición en español), vol. 5, pp. 80-83

KAPLAN, M. (1983): Formación del Estado Nacional en América Latina. Amorrortu Editores, Buenos Aires, $462 \mathrm{pp}$.

LASSO TISCAREÑO, R. (2002): Dimensiones de la Globalización. Algunos avances teóricos generales; Momento Económico. UNAM, México, 155 pp.

LOPRESTI, R. P. (2007): Constituciones del Mercosur (2a edición). Editorial La Ley. Buenos Aires, $302 \mathrm{pp}$.

MACKINDER, H. J. (1904) «The Geographical Pivot of History», Geographical Journal, Royal Geographical Society London, vol. XXIII, 436 pp. 
MALDONADO, C. QUIROGA, P. (1988) El prusianismo en las FF.AA. chilenas. Editorial Documentas. Santiago de Chile.

PABÓN NÚÑEZ, L. (1997): El pensamiento político del Libertador. Planeta Colombiana S.A. Santafé de Bogotá, 254 pp.

PAINTER, J. (1995): Política, geografía y geografía política, Arnold. London, 445 pp.

PITTMAN, H. (1981): La Geopolítica en los países ABC: una comparación; tesis de Ph.D. en la Universidad Americana, Microfilmes de la Universidad, MI 82-04557. Ann Arbor City. Michigan State. U.S.A.

PNUMA (2010): Perspectivas del medio ambiente: America Latina y el Caribe, Documento de trabajo ONU. Panamá, 98 pp.

PRATT, J. (1972): The origin of manifest destiny. American Historical Review. Vol. 3, 937 pp.

QUAGLIOTTI DE BELLIS, B. (2007): «IV Flota impone su presencia en el Atlántico Sur». Revista La Onda digital. Uruguay. http://www.unep.org/geo/geo3/english/pdfs/chapter2-5_Freshwater. pdf (consultado el 12 enero de 2012)

RODRÍGUEZ DÍAZ, M. (2003): El Destino Manifiesto. El pensamiento expansionista de Alfred Thayer Mahan. 1890-1914. Editorial Porrúa. México, 283 pp.

RUCINQUE, H.F. (2006): «Geografía política: Tarea y retos para los geógrafos del Tercer Mundo». GeoTrópico, Editorial, vol. 3 (1), www.geotropico.org/3_2_Editorial.html (consultado el 10 de noviembre de 2011).

SCHOULTZ, L. (1998): Beneath the United States. A History of U.S. Policy Toward Latin America. Cambridge, Mass. ISBN 0-674-92276. Harvard Univ. London: pp. 39-58.

UNEP (2003): Water resources management in Latinamerica and Caribbean. Panamá, 123 pp. Univ. Texas. http://www.unep.org/geo/geo3/english/pdfs/chapter2-5_Freshwater.pdf (consultado el 13 enero de 2012). 